\title{
O Software GeoGebra: Uma Estratégia de Aprendizagem Aplicada no Estudo de Funções Trigonométricas
}

\author{
GeoGebra software: an applied learning strategy in the study of trigonometric
} functions

\author{
Joaildo Maia ${ }^{1}$ e Marcelo Gomes Pereira ${ }^{2}$
}

${ }^{1}$ Instituto Federal de Educação, Ciência e Tecnologia do Rio Grande do Norte - IFRN, Brasil Mestre em Ensino de Matemática. Docente do Instituto Federal de Educação, Ciência e Tecnologia do Rio Grande do Norte - IFRN,

${ }^{2}$ Doutor, Universidade Federal do Rio Grande do Norte, UFRN, Brasil

\section{Resumo}

O presente artigo se fundamenta em um recorte do trabalho de pesquisa de pós-graduação "Stricto Sensu" intitulado O Ensino das Funções Trigonométricas através do Software GeoGebra, trabalho de conclusão para obtenção do título de mestre do Profmat (Mestrado profissional em matemática em rede nacional). Com esse trabalho, buscou-se suprir as deficiências enfrentadas por boa parte dos alunos quando eram estudadas as funções trigonométricas seno e co-seno. Para isso, propôs-se a utilização do software GeoGebra na realização de uma sequência de atividades sobre o conteúdo abordado. A pesquisa teve uma abordagem qualitativa, baseada em observações das atividades realizadas pelos alunos do $2^{\circ}$ Ano do Ensino Médio do Instituto Federal do Rio Grande do Norte - IFRN - Campus Caicó. As atividades possibilitaram verificar algumas dificuldades encontradas pelos alunos, assim como a interação existente entre eles durante a realização das tarefas. Os resultados obtidos foram satisfatórios, pois indicam que a utilização do software contribuiu para uma melhor compreensão desses conceitos matemáticos estudados.

Palavras-chave: Matemática. Funções trigonométricas. GeoGebra.

\begin{abstract}
This article is based on a clipping from research graduate "stricto sensu" entitled The Education of Trigonometric Functions through Software GeoGebra, job completion to obtain the title of Master Profmat (Professional Master's in mathematics in national network). To this study, we sought to address the weaknesses faced by most students when they were studying trigonometric functions sine and cosine. For this, we proposed the use of software GeoGebra in performing a sequence of activities about the content studied. The research was a qualitative approach, based on observations of the activities performed by the students of 2nd year of high school Federal Institute of Rio Grande do Norte - IFRN - Campus Caicó. The activities enabled check some difficulties encountered by students, well as the interaction between them during the tasks. The results were satisfactory, since they indicate that the use of software contributed to a better understanding of these mathematical concepts studied.
\end{abstract}

Keywords: Mathematics. Trigonometric functions. GeoGebra. 


\section{Introdução}

O ensino da Matemática, ao longo de sua história, vem passando por grandes mudanças no tocante à forma como se concebe o processo de aprendizagem dos alunos. Acredita-se que tais mudanças venham ocorrendo devido à necessidade de aproximar cada vez mais esse ensino da realidade dos mesmos, por meio de atividades práticas nas quais os alunos se sintam partes integrantes desse processo, tornando-os capazes de analisar e resolver situações problema relacionados à sua vida diária.

Estudos sobre o ensino da trigonometria apontam uma grande deficiência dos alunos no tocante aos conceitos básicos, como as definições de seno, co-seno e tangente, redução de arcos ao primeiro quadrante, entre outros. Tal deficiência pode ser atribuída à falta de conhecimentos prévios ou por ser ensinado de modo abstrato sem nenhuma aplicação prática, baseado apenas na transmissão de fórmulas e regras, não apresentando nenhum significado para a maioria dos alunos. Pois, de acordo com os Parâmetros Curriculares Nacionais - PCN+ (2002), apesar de sua importância, o ensino da trigonometria é apresentado desconectado das aplicações, dando bastante ênfase ao cálculo algébrico de identidades e equações em detrimento de aspectos importantes das funções trigonométricas e análise de seus gráficos. Sendo assim, devem ser asseguradas as aplicações da trigonometria na resolução de problemas que envolvam medições, em especial o cálculo de distâncias inacessíveis e para construir modelos que correspondem a fenômenos periódicos.

Partindo do exposto anteriormente, sentiu-se a necessidade de desenvolver uma pesquisa a qual abordasse de maneira significativa as funções trigonométricas, partindo de situações das quais o aluno pudesse participar da construção desse conhecimento; tentando assim, desfazer a antipatia que boa parte dos estudantes tem pelo ensino da Matemática e, de modo especial, pelas funções trigonométricas.

Com o intuito de acabar com essa antipatia, propôs-se a utilização do software GeoGebra na realização de uma sequência de atividades sobre o conteúdo estudado. As atividades possibilitaram verificar algumas dificuldades e êxitos dos alunos; assim como a interação existente entre eles durante a realização das tarefas.

O referido trabalho apresenta-se estruturado em três partes; a primeira apresenta uma análise teórica e prática da utilização de recursos computacionais no estudo das funções trigonométricas seno e co-seno, como também do uso do software GeoGebra enquanto recurso didático e a metodologia utilizada no referido trabalho; a segunda descreve as atividades aplicadas em sala de aula, relatando os objetivos e os resultados observados e por fim, na terceira parte temos a discussão.

\section{Funções trigonométricas e GeoGebra: Relacionando teoria e prática}

Ao longo de muitos anos atuando como docente da disciplina Matemática no Ensino Médio sentia-se as dificuldades dos estudantes na aprendizagem dos conceitos da trigonometria e, em particular, na construção dos gráficos das funções seno e co-seno. Concebemos que uma parcela dessa dificuldade seja atribuída à forma como os conteúdos são repassados em sala de aula e também ao método como estes são abordados pelos livros didáticos e por grande parte dos professores de modo mecânico, sem questionamentos de sua aplicação na vida diária.

Frente a isso, surge a necessidade de se buscar novos recursos didáticos que possam ser utilizados nas aulas de Matemática, possibilitando-lhes uma aprendizagem onde o aluno se sinta componente do processo. Então, propõe-se a introdução das tecnologias digitais no ensino das funções trigonométricas, a fim de renovar um ensino meramente expositivo, proporcionando aos alunos a possibilidade de se tornarem agentes do seu próprio conhecimento, uma vez que o uso do computador é indispensável para a vida cotidiana dos cidadãos e a escola não pode fugir dessa realidade.

Percebe-se um avanço tecnológico cada vez mais presente na vida dos cidadãos, tornando-se um instrumento essencial de trabalho. Por isso, não se pode pensar em uma educação sem fazer uso de tais recursos e o ensino da Matemática não pode se desvincular dessa realidade, tendo em vista que o uso das tecnologias digitais nas aulas de matemática tem sido alvo de debates 
sobre os efeitos causados na aprendizagem. Nesse sentido, cabe ao professor criar condições favoráveis para o seu uso, de modo que seus efeitos sejam benéficos para o processo de ensino e aprendizagem, de forma que o aluno possa interagir dentro do processo, como também desenvolver outros conhecimentos e habilidades.

Compreende-se que a educação aliada à tecnologia proporciona ao aluno uma nova maneira de aprendizagem e ao professor uma nova metodologia de ensino. $\mathrm{O}$ uso do computador como uma ferramenta didática torna a aula mais dinâmica, pois insere o aluno no processo de ensino e aprendizagem de forma autônoma, já que é por meio do computador que existe a possibilidade de interação através do reforço da aprendizagem, do despertar da curiosidade, do incentivo à criatividade e à formulação de conceitos matemáticos.

Baseado no que afirma Valente (1999), a atividade de uso do computador pode ser feita tanto para continuar transmitindo a informação para o aluno, quanto para reforçar o processo de instrução deste, criando condições para a construção do seu conhecimento.

Assim, a abordagem que usa o computador como meio para transmitir a informação ao aluno quebra a dinâmica tradicional do ensino da Matemática, pois o computador passa a ser visto como um veículo que além de informatizar as salas da escola, também poderá ser utilizado como suporte metodológico nas aulas de Matemática.

A esse respeito, Mercado (2002, p. 30) afirma que "um professor consciente e crítico é capaz de compreender a influência da tecnologia no mundo moderno e é capaz de colocá-la a serviço da educação e da formação de seus alunos, articulando as diversas dimensões de sua prática docente, no papel de um agente de mudança".

Nesse sentido, os softwares matemáticos podem ser grandes aliados nas aulas de Matemática, mas é necessário um bom planejamento do professor para que estes se tornem um importante aliado no processo de ensino e aprendizagem e que o aluno tenha clareza de que a sua utilização é importante dentro do processo de aprendizagem.

Dentre os vários softwares matemáticos existentes, destaca-se o GeoGebra, um software criado por Markus Horhenwarter da Universidade de Salzburg para a educação matemática nas escolas, cujo conteúdo reúne Geometria, Álgebra e Cálculo, sendo empregado no ensino e aprendizagem da matemática em qualquer nível ou modalidade de ensino por possuir uma interface de fácil acesso.

A interface do GeoGebra é formada pelas seguintes partes: Janela de visualização (ou gráfica), janela de álgebra e um campo de entrada de texto. $\mathrm{Na}$ janela gráfica existe um sistema de eixos cartesianos, o qual permite ao usuário construir gráficos de funções e quando for trabalhar com construções geométricas, o software permitirá a omissão deste. No campo de entrada é possível digitar coordenadas, equações, comandos, operações, funções, entre outros, sendo que tudo o que é digitado neste campo aparece na janela de álgebra. O que for digitado no campo de entrada e que é possível ser representado geometricamente ou graficamente, aparecerá na janela gráfica. Da mesma forma, tudo o que for feito na janela gráfica aparecerá na janela de álgebra na forma algébrica.

Através do software GeoGebra foi possível a manipulação de recursos disponíveis, entre os quais, mover objetos na tela e alterar o período e o conjunto imagem das funções estudadas, possibilitando ao aluno ser agente do seu próprio conhecimento, sendo capaz de formular conceitos matemáticos, dinamizando assim, o processo de ensino da Matemática. Essa dinamização foi proposta no estudo das funções trigonométricas (seno e co-seno), a qual permitiu a construção de gráficos e o uso de atividades, as quais serão detalhadas abaixo.

\section{Descrição das atividades práticas e metodologia da pesquisa}

A intenção do referido trabalho foi mostrar que é possível ensinar e aprender as funções seno e co-seno aliadas ao uso do computador com o auxílio do software GeoGebra como ferramenta de apoio, oportunizando ao aluno explorar propriedades e realizar as atividades a partir de uma sequência de passos até chegar ao gráfico da função pedida, contribuindo para uma compreensão da Matemática que seja significativa e aplicável em suas vidas cotidianas.

É válido ressaltar que as atividades foram desenvolvidas em uma turma de $2^{\circ}$ ano do 
Curso Técnico de Nível Médio em Eletrotécnica integrado ao ensino médio do Instituto Federal de Educação, Ciência e Tecnologia do Rio Grande do Norte - IFRN - Campus Caicó, composta por 43 alunos na faixa etária entre 15 e 19 anos. O que motivou a escolha desta turma foi o fato de que o autor é o professor desta e ele já tinha o conhecimento das dificuldades encontradas como: indisciplina, limitação de aprendizagem por parte de alguns alunos.

Para a realização das atividades foi utilizada como metodologia a observação participante, tomando como referência as ações dos alunos nas resoluções das atividades propostas e a observação no momento em que estas eram aplicadas. Assim, foi possível ter uma boa clareza na coleta dos dados e na análise dos resultados.

Para fundamentar as atividades propostas analisou-se algumas coleções citadas pelo PNLEM", entre elas "Conexões com a Matemática", publicado pela editora Moderna, sendo Juliane Matsubara Barroso a editora responsável e a coleção "Novo Olhar Matemática" de Joamir Souza, publicada pela editora FTD, cujas propostas de trabalho se assemelham a que se pretende desenvolver.

Na coleção "Conexões com a Matemática", a obra faz o estudo das funções trigonométricas seno e co-seno de modo bem objetivo, utilizando o ciclo trigonométrico para definir tais funções. $\mathrm{Na}$ construção dos respectivos gráficos, Barroso (2010) faz uso de uma tabela de valores para o arco $x$, a qual expande a construção para outros valores além de uma volta (ou seja, repete-se para $x>2 \pi$ e $x<0$ ).

Com relação aos gráficos de funções mais complexas (funções do tipo $f(x)=a+b$.sen $(c x+$ d) ou $\mathrm{f}(\mathrm{x})=\mathrm{a}+\mathrm{b} \cdot \cos (\mathrm{cx}+\mathrm{d})$, com $a, b, c$ e $d$ reais e $b \neq 0$ e $c \neq 0$ ), Barroso (2010) utiliza uma sequência de passos, onde inicialmente constróise o gráfico da função simples (seno ou co-seno) e, a partir dele, com a introdução de novos elementos, obtém-se o gráfico da função

1 PNLEM - Programa Nacional do Livro Didático para o Ensino Médio. O Ministério da Educação (MEC) distribui os livros didáticos às unidades de ensino médio de todo o país por intermédio do FNDE - Fundo Nacional de Desenvolvimento da Educação. desejada. Utilizar-se-á um procedimento semelhante ao abordado pela autora na descrição das atividades a serem desenvolvidas.

$\mathrm{Na}$ outra coleção, "Novo Olhar Matemática", Souza (2010) define as funções seno e co-seno no conjunto dos números reais por meio da associação $\mathrm{x}$ (em radianos) a sen $\mathrm{x}$, utilizando, para isso, a representação de conjuntos através do diagrama de Venn ${ }^{2}$.

Em seguida, para representar graficamente as funções, Souza (2010) construiu uma tabela de valores com elementos $\mathrm{x}, \mathrm{y}=\operatorname{sen} \mathrm{x}$ ou $\mathrm{y}=\cos \mathrm{x} e$ o par ordenado $(x, y)$, utilizando valores $x \in[0$, $2 \pi]$, expandindo em seguida a representação para todo o domínio $\mathrm{D}=\mathbb{R}$.

Após a análise das duas obras percebeu-se algumas características semelhantes entre ambas, entre as quais se destaca a construção dos gráficos de uma determinada função, tendo por base o gráfico da função elementar. Um fato interessante mostrado pelo autor é a obtenção do gráfico da função $f(x)=\cos x$ a partir do gráfico da função $g(x)=\operatorname{sen} x$, transladado $\frac{\pi}{2}$ unidades para a esquerda.

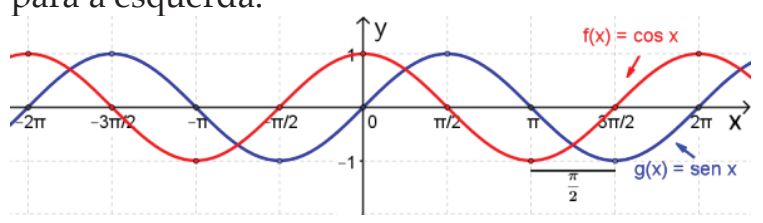

Figura 1: Gráficos das funções f e $g$

O autor destaca também a variação que ocorre entre os gráficos das funções e os respectivos períodos e imagens das funções $\mathrm{f}(\mathrm{x})=$ $a+b \cdot \operatorname{sen}(c x+d)$ ou $f(x)=a+b \cdot \cos (c x+d)$ quando as constantes $a, b, c$ e $d$ são modificadas.

A contextualização que existe entre teoria e prática nas atividades propostas para os alunos é outra semelhança que merece ser lembrada, pois ao mesmo tempo em que os autores abordam as funções trigonométricas, utilizam situações práticas do dia a dia nas representações gráficas de tais funções.

Nesse sentido, D’Ambrósio (2005, p.117) destaca que:

[...] o acesso a um maior número de instrumentos e de técnicas intelectuais dá, quando devidamente contextualizado, muito maior capacidade de enfrentar

\footnotetext{
${ }^{2}$ John Venn - Matemático inglês; 1834 - 1923.
} 
situações e problemas novos, de modelar adequadamente uma situação real para, com esses instrumentos, chegar a uma possível solução ou curso de ação, isto é aprendizagem por excelência, isto é, capacidade de explicar, de apreender e compreender, de enfrentar, criticamente situações novas. Aprender não é o mero domínio de técnicas, habilidades e nem de memorização de algumas explicações e teorias.

Para exemplificar o uso das funções trigonométricas em uma vivência prática da vida, Souza (2010, p. 52), destaca o ciclo cardíaco modelado matematicamente por meio da seguinte situação:

Suponha que a pressão sanguínea de um indivíduo, a partir de um instante inicial $\mathrm{t}=0$, possa ser representado aproximadamente pela função $\mathrm{f}(\mathrm{t})=95-25 \operatorname{sen}\left(\frac{5 \pi}{2} \mathrm{t}+\frac{\pi}{2}\right)$, sendo $t o$ tempo dado em segundos e $f(t)$ a pressão sanguínea em milímetros de mercúrio $t$ segundos após o instante inicial.

Assim, percebe-se que há uma conexão entre teoria e prática, de modo que o aluno compreenda que o ensino da Matemática não está desvinculado do mundo real.

De acordo com os PCN+ (2002), aprender Matemática de uma forma contextualizada, integrada e relacionada a outros conhecimentos traz em si o desenvolvimento de competências e habilidades que são essencialmente formadoras, à medida que instrumentalizam e estruturam o pensamento do aluno, capacitando-o para compreender e interpretar situações a fim de se apropriar de linguagens específicas, argumentar, analisar e avaliar, tirar conclusões próprias, tomar decisões, generalizar e para muitas outras ações necessárias à sua formação.

Dessa forma, observa-se que os livros analisados se assemelham a proposta apresentada neste trabalho, com o diferencial de que os mesmos não utilizam nenhum recurso tecnológico para desenvolver as atividades.

\section{Relato de experiência em uma turma do ensino médio}

A aplicação das atividades em sala de aula transcorreu sem maiores dificuldades, uma vez que apresentou uma abordagem metodológica bastante familiar aos alunos, tendo em vista que a informática faz parte de suas vidas.

As atividades foram elaboradas de modo que os alunos utilizaram o software GeoGebra na construção dos gráficos das referidas funções, tendo sido necessário uma sequência de oito aulas de 45 minutos para desenvolver as quatro atividades propostas que serão relatadas a seguir.

\section{$1^{\underline{a}}$ Atividade}

Objetivo: levar ao conhecimento dos alunos o software GeoGebra e verificar a sua aplicação no estudo das funções seno e co-seno.

Fez-se, inicialmente, uma explanação sobre o estudo das funções trigonométricas seno e coseno e, em seguida, alguns questionamentos, abordando algumas temáticas como: a importância dessas funções em nossas vidas e de que modo se percebe a presença dos fenômenos periódicos em situações cotidianas, o conhecimento do software GeoGebra e qual a importância de utilizar o computador como ferramenta didática na construção dos gráficos de tais funções.

Após a conversa informal, assistiu-se ao vídeo "Tutorial GeoGebra - parte I", o qual mostra os recursos disponíveis e que se pode utilizar no software. Logo após, utilizando o projetor de multimídia, o professor mostrou, passo a passo, a construção do ciclo trigonométrico, como também, dos gráficos das funções seno e co-seno a partir da circunferência trigonométrica, considerando o intervalo de $0^{\circ}$ a $360^{\circ}$.

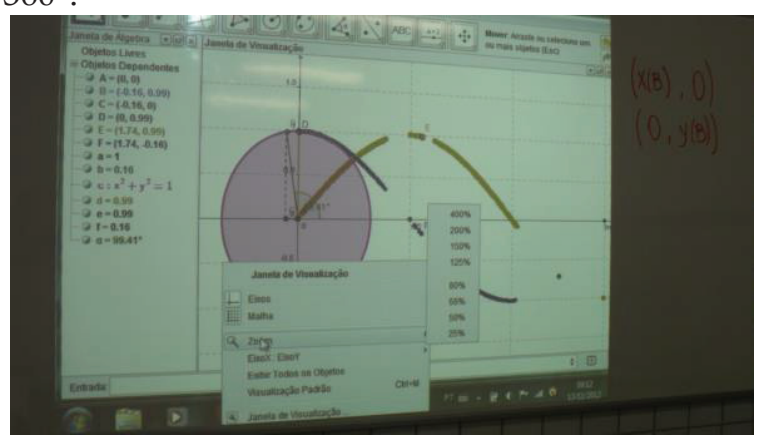

Figura 2: Construção do ciclo trigonométrico pelo professor

Percebeu-se, pois, que os alunos se mostraram bastante atentos às informações do vídeo e muito entusiasmados com a construções citadas acima. 
No final da aula, alguns alunos relataram que acharam a aula interessante e demonstraram interesse em utilizar o GeoGebra, uma vez que o mesmo oferece uma série de recursos capaz de dinamizar as aulas.

\section{$2^{\underline{a}}$ Atividade}

Objetivo: permitir que os alunos construam os gráficos das funções seno e co-seno por meio do software GeoGebra, utilizando os vários recursos oferecidos pelo mesmo.

Para a realização desta atividade a turma foi deslocada para um dos laboratórios de informática e dividida em grupos de dois ou três alunos, pois o laboratório utilizado só dispunha de 21 computadores.

De início, os alunos utilizaram de forma livre, por alguns minutos, o software, realizaram algumas construções geométricas e puderam perceber as potencialidades e recursos disponíveis no GeoGebra. Em seguida, seguindo orientações do professor, construíram o ciclo trigonométrico e os gráficos das funções seno e co-seno.

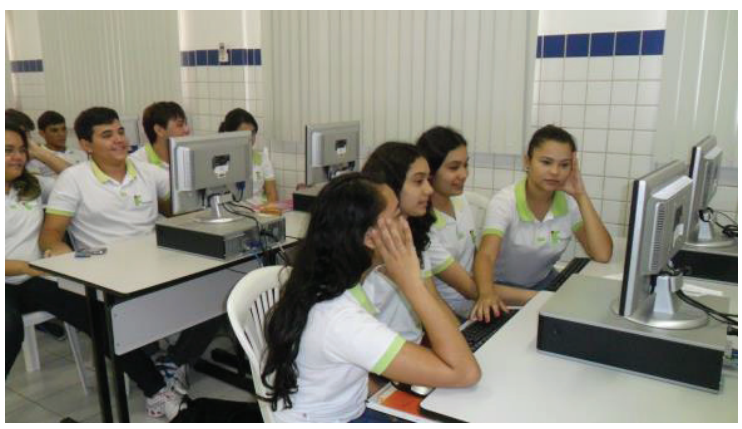

Figura 3: Alunos realizando a atividade

Esta atividade permitiu aos alunos conhecerem melhor o GeoGebra e algumas de suas potencialidades. Comprovaram que ao deslocar o gráfico da função seno em $\frac{\pi}{2}$ unidades para a esquerda, obtém-se o gráfico da função co-seno. Vale ressaltar que um momento para o qual eles se sentiram bastante empolgados foi o da aplicação do recurso que permite a animação dos gráficos.

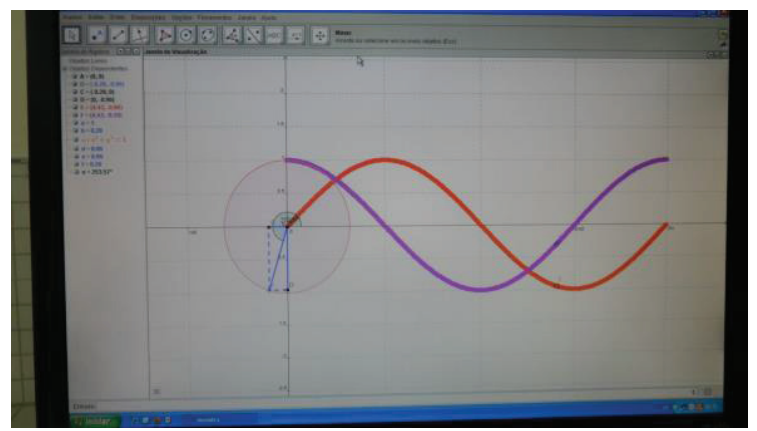

Figura 4: Atividade realizada por um dos grupos

Observou-se durante a realização da atividade uma grande interação entre os alunos e o software. Os discentes desenvolveram a atividade sem maiores dificuldades e quando necessário solicitavam a presença do professor para sanar algumas dúvidas. Um fato curioso que chamou a atenção do professor foi quando um aluno, ao final da aula, aproximou-se do mesmo e disse que nunca havia imaginado que fosse possível aprender Matemática de uma forma diferente do método tradicional que costumava ver nas aulas. Esse comentário do aluno vem ratificar a importância de se utilizar recursos diversos para o ensino da Matemática, oferecendo-lhes condições para que percebam a importância desta ciência em suas vidas através de situações onde possam vivenciar o conteúdo estudado em sala de aula, ao invés de continuarmos a ministrar somente aulas expositivas, que não contribuem para o desenvolvimento do raciocínio.

\section{$3^{\underline{a}}$ Atividade}

Objetivo: possibilitar ao aluno a construção de gráficos de funções do tipo $f(x)=a+b$.sen $(c x+$ d) ou $g(x)=a+b \cdot \cos (c x+d)$, tendo por base o gráfico da respectiva função (seno ou co-seno), utilizando caneta e papel e, em seguida, repetir a mesma atividade aplicando o GeoGebra, visando a observação de que com o acréscimo de novos elementos o gráfico sofre uma transformação.

Baseado nas afirmações de Brousseau (2001) e Oliveira (2009), é essencial que o processo de aprendizagem da Matemática dos estudantes se dê através de problematizações que permitam reflexão e autonomia.

Sendo assim, para que ocorra uma aprendizagem na qual o aluno adquira autonomia, a fim de solucionar as situações propostas, é importante oferecer condições para que ele se sinta parte integrante do processo. 
Jara isso nao se pode esquecer de que se vive em uma sociedade em constantes mudanças e com avanços tecnológicos cada vez mais presentes em nossas vidas. Por isso, faz-se necessário o uso de novas tecnologias, uma vez que o ensino da Matemática não pode se desvincular do mundo atual.

Baseando-se no que foi elucidado anteriormente, primeiro foi feita uma apresentação à turma através de slides sobre o comportamento do gráfico de determinada função do tipo $f(x)=a+b$.sen $(c x+d)$ ou $g(x)=a$ + b.cos $(c x+d)$ tendo por base o gráfico da função $f_{1}(x)=$ sen $x$ ou $g_{1}(x)=\cos x$, visto que ambos apresentam características semelhantes.

Neste caso, observou-se o que acontece com a função original quando ocorre uma variação dos parâmetros reais $a, b, c$ e $d$, com $b$ e $c$ não nulos; como também, a mudança de período e imagem das funções com tais variações.

Em seguida, foi pedido aos grupos que construíssem os gráficos, por exemplo, das funções $f(x)=$ sen $x$ e $g(x)=3$.sen $x$. Para realizar a tarefa, inicialmente os alunos construíram uma tabela atribuindo os valores para o arco $\mathrm{x}$, considerando $x \in[0,2 \pi]$, depois calcularam as respectivas imagens através da função $f(x)=$ sen $x$ e representaram em seguida, os pares ordenados no plano cartesiano, obtendo a representação desejada. Para o gráfico da função $\mathrm{g}$, foi necessário apenas multiplicar a imagem de f por 3 e ampliar verticalmente em 2 unidades o gráfico de $\mathrm{f}$. $\mathrm{O}$ período da função $\mathrm{g}$ permaneceu o mesmo, porém na imagem houve uma ampliação em relação à função $f$.

Posteriormente, utilizando o GeoGebra, foi orientado aos alunos que realizassem a mesma tarefa, para isso na caixa de entrada da tela do software foi digitado a função $f(x)=\sin x(\operatorname{sen} x)$ e, em seguida, apertado a tecla enter. Na janela de álgebra apareceu a função inserida e na janela de visualização apareceu a senoide (gráfico da função seno). Repetiu-se o mesmo procedimento na construção do gráfico de $g$, onde no campo de entrada digitou-se $\mathrm{g}(\mathrm{x})=3^{*} \sin \mathrm{x}$.

Nesta atividade, os alunos tiveram oportunidade de verificar na prática as informações expostas nos slides e observar que o gráfico da função $y=$ b.sen $x$ sofreu uma ampliação vertical, pois $b=3>1$. De acordo com o apresentado nos slides, com relação ao parâmetro $b$, vê-se que se $|\mathrm{b}|>1$ ocorre uma ampliação do gráfico da função e se $|\mathrm{b}|<1$, o gráfico se comprime verticalmente.

Outro momento relevante da atividade ocorreu quando foi pedido aos alunos que construíssem uma sequência de quatro gráficos envolvendo as funções seno e co-seno, iniciando sempre com o gráfico da função simples e com a inserção de novos elementos permitiu se chegar a representação gráfica de todas as funções solicitadas. À medida que se construía um novo gráfico, tinha-se a possibilidade de omitir a função anterior. Isso pode ser feito desmarcando a função na janela de álgebra.

É importante destacar que nesta atividade observou-se uma interação bastante expressiva dos alunos durante a sua realização, quando eles na construção dos gráficos, ao passo que iam acrescentando novos dados, tiveram a oportunidade de omitir a função anterior representada, assim como, comprovar a mudança de período, no caso de a constante $c$ ser alterada e de imagem, no caso de a alteração se dar com a constante $b$, ou ambos, no caso de as duas variarem. Foi um momento que se trabalhou com todo o domínio ou com um subconjunto do domínio, a considerar, por exemplo, $[0,2 \pi]$, visto que ele poderia ser limitado pelas margens da janela de visualização do GeoGebra.

Baseado no que afirma Valente (1995), o computador é um instrumento que permite ao aluno fazer uso do material com outras características não permitidas no papel como: animação, som e a manutenção do controle da performance do aprendiz..

\section{$4^{\underline{a}}$ Atividade}

Objetivo: oferecer condições ao aluno para que, partindo de situações práticas e do uso do software GeoGebra, consiga entender, como também visualizar a aplicação dos fenômenos periódicos modelados matematicamente.

No primeiro momento, no laboratório de informática, foi distribuída a seguinte situação à turma, adaptada de Barroso (2010, p. 78):

Em certa cidade litorânea, a altura $h$ da maré (em metro), em função do tempo, é dada pela expressão $\mathrm{h}(\mathrm{x})=3+2 \cdot \operatorname{sen}\left(\frac{\pi}{6} \cdot \mathrm{x}\right)$, na qual $x$ é o tempo, medido em hora, a partir da meia-noite ( $\mathrm{x}$ $=0$ representa meia-noite). A função seno que 
compõe a função $h$, descreve o comportamento do tipo periódico da maré. Esboçar o gráfico da função, determinando os respectivos período e imagem.

Para a construção do gráfico da função $h$, usando o GeoGebra, foi apresentada a seguinte sequência de passos, tomando como referência os passos apresentados no volume 2 da coleção "Conexões com a Matemática" (BARROSO, 2010, p. 69).

Para a análise dessa função, vamos partir do gráfico da função $f(x)=\operatorname{sen} x$, considerando $o$ intervalo $[0,2 \pi]$ e em cada caso destacar os respectivos período e imagem.

$1^{\circ}$ passo: $\operatorname{sen} x \rightarrow \operatorname{sen}\left(\frac{\pi}{6} \cdot x\right)$

Construção do gráfico da função $f(x)=\operatorname{sen} x$.

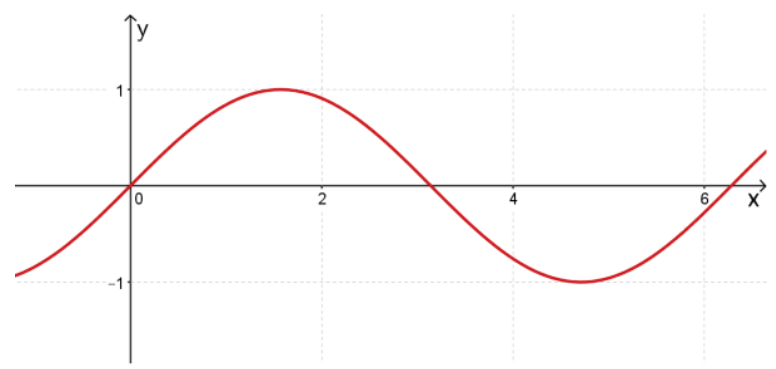

Figura 5: Gráfico da função $f$

Observa-se que a função $\mathrm{f}$ tem período $6,3 \mathrm{~h}$ (aproximadamente) e imagem [-1, 1].

Construção do gráfico da função $\mathrm{g}(\mathrm{x})=$ sen $\left(\frac{\pi}{6} \cdot x\right)$.

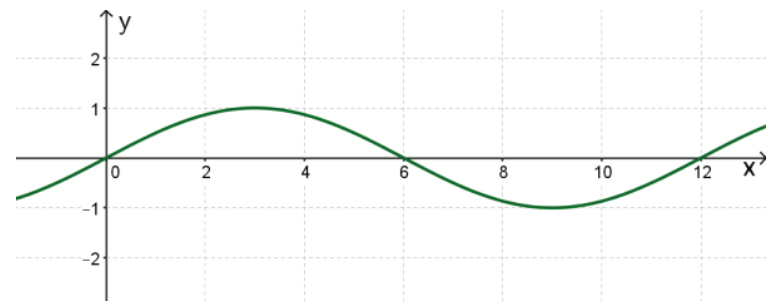

Figura 6: Gráfico da função g

O gráfico obtido sofreu uma ampliação no período em relação à função $\mathrm{f}$. Nesse caso, $\mathrm{o}$ período é $12 \mathrm{~h}$ e a imagem permanece a mesma.

$2^{\circ}$ passo: $\operatorname{sen}\left(\frac{\pi}{6} \cdot x\right) \rightarrow 2 \cdot \operatorname{sen}\left(\frac{\pi}{6} \cdot x\right)$

Construção do gráfico da função $j(x)=2$.sen $\left(\frac{\pi}{6} \cdot x\right)$.

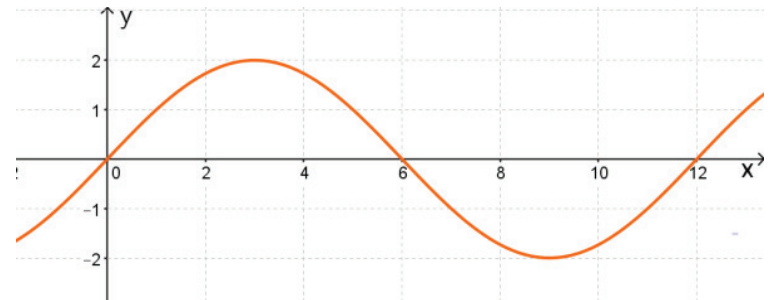

Figura 7: Gráfico da função j

Nesse caso, o gráfico sofreu uma ampliação vertical alterando a imagem, passando para $[-2$, 2], porém continua o mesmo período.

$3^{\circ}$ passo: $2 \cdot \operatorname{sen}\left(\frac{\pi}{6} \cdot x\right) \rightarrow 3+2 \cdot \operatorname{sen}\left(\frac{\pi}{6} \cdot x\right)$

Construção do gráfico da função $h(x)=3+$ $2 \cdot \operatorname{sen}\left(\frac{\pi}{6} \cdot x\right)$.

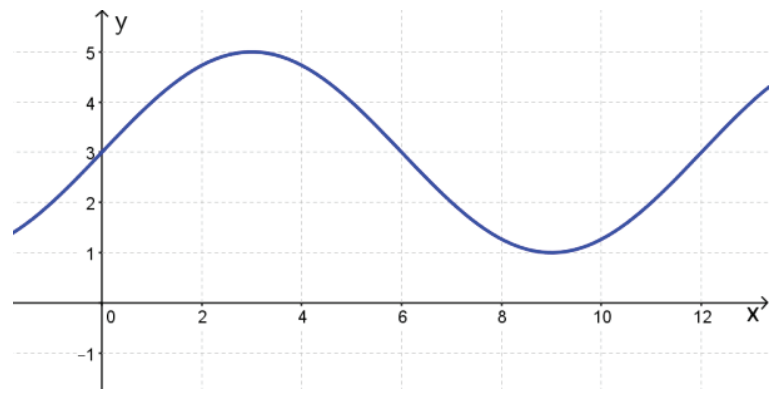

Figura 8: Gráfico da função $h$

O gráfico foi transladado 3 unidades para cima, permanecendo com o mesmo período e sofrendo uma alteração na imagem. Portanto, o período e a imagem da função $h$ são, respectivamente, $12 \mathrm{~h}$ e $[1,5]$.

De tal modo, vê-se que as funções trigonométricas seno e co-seno são usadas na modelagem matemática de fenômenos naturais periódicos, uma vez que esses fenômenos tem relação com a vida diária dos alunos e, portanto, é essencial que compreendam os conceitos e abstraiam a relação que existe entre a teoria e a prática.

Os fenômenos periódicos são aqueles que se repetem de forma cíclica a cada intervalo de tempo e que estão limitados entre um valor máximo e um valor mínimo, a exemplo do que ocorre com as funções citadas acima. Vale ressaltar que esse intervalo de tempo em que a maré completa um ciclo (no caso do exemplo, a cada 12 horas) representa o período e a oscilação da maré entre $1 \mathrm{~m}$ e $5 \mathrm{~m}$, respectivamente, as alturas mínima e máxima, é o conjunto imagem da função. Destaca-se ainda a amplitude da 
função representada pela distância entre o nível do mar (momento em que se inicia a observação) e o ponto em que a maré atinge o seu máximo ou o seu mínimo.

A partir da construção dos gráficos, foi possível observar as transformações sofridas pela função à medida que eram introduzidos novos elementos, ocasião em que houve uma discussão a respeito da importância do estudo desses fenômenos para a nossa vida diária.

No segundo momento da aula foi distribuída uma atividade aos alunos contendo seis questões, semelhantes à descrita anteriormente, envolvendo as funções trigonométricas estudadas, para serem respondidas com o auxílio do software GeoGebra. Em algumas delas, pedia aos alunos para que construíssem os gráficos de determinadas funções e, logo após, respondessem as perguntas. Já em outras, eram dados elementos que os permitiam compor as funções para, em seguida, fazer a representação gráfica.

Foi uma atividade, através da qual se teve condições de analisar o comportamento da turma durante o transcorrer da atividade, como também, de analisar a natureza das respostas escritas e gráficas.

Por meio desta atividade teve-se oportunidade de avaliar a participação e o desempenho dos alunos no decorrer da aula. $\mathrm{O}$ resultado foi satisfatório, pois a maioria não sentiu dificuldades na realização das tarefas, tendo um bom desempenho. Desse modo, o objetivo do autor foi atingido.

\section{Considerações finais}

Considerando-se a experiência de anos anteriores na qual sentia-se as dificuldades apresentadas pelos alunos do Ensino Médio no estudo da trigonometria e, em particular, na construção dos gráficos das funções trigonométricas seno e co-seno, foi proposto esse trabalho com o objetivo de facilitar a compreensão desses conceitos, utilizando, para tanto, uma sequência de atividades desenvolvidas com o auxílio do software GeoGebra.

Durante a realização das atividades foi possível observar o desempenho dos alunos, considerando-se o modo como eles resolveram essas atividades, a interação que existiu entre os mesmos e o software utilizado, assim como, entre os componentes dos grupos.

Fundamentando-se ainda na experiência vivenciada em outros anos onde o estudo das funções trigonométricas era desenvolvido sem fazer uso de tal recurso, percebeu-se que houve uma evolução no processo de ensino e aprendizagem, uma vez que ocorreu uma grande participação da turma na realização das atividades propostas e uma melhor compreensão dos conceitos trigonométricos abordados em cada uma delas.

Verificou-se, ainda, que a interatividade proporcionada pelo software GeoGebra contribuiu para que os alunos articulassem melhor o raciocínio lógico matemático na busca de solução para as situações propostas, sendo assim, um articulador entre teoria e prática.

Porém, é importante ter consciência de que quando o professor se dispõe a trabalhar com uma tecnologia digital deve ter em mente que essa, por si só, não é suficiente para garantir sucesso no processo de ensino e aprendizagem, mas que pode possibilitar avanços significativos no decorrer desse processo.

Desse modo, considera-se que os objetivos propostos na elaboração desse trabalho foram atingidos, pois as atividades desenvolvidas com a utilização do recurso computacional possibilitaram aos alunos uma maior interação entre teoria e prática, pois os mesmos conseguiram com o manuseio de tal ferramenta construir e analisar gráficos das funções seno e co-seno, começando com a construção do ciclo trigonométrico seguido dos gráficos das funções elementares até chegar aos gráficos das funções mais complexas.

Dessa forma, espera-se que esse trabalho possa contribuir para que professores de Matemática aprimorem seus conhecimentos e entendam que ensinar e aprender dentro de uma sociedade informatizada requer a necessidade de trabalhar com novas metodologias de ensino, acrescentando novos significados aos conteúdos e possibilitando aos estudantes usar as informações recebidas para suprir suas dificuldades, como também, adquirir consciência de que vivem em um mundo em constante mudança.

Um mundo sujeito a novas concepções acerca do processo de ensino da Matemática, que vislumbre novas metodologias de ensino e que 
proporcione aos alunos um processo de aprendizagem mais significativo e prazeroso na busca desse conhecimento.

\section{Agradecimentos}

A Deus, por fazer parte de minha vida e estar sempre presente em todos os momentos.

Aos professores do curso, com os quais aperfeiçoamos nossos conhecimentos.

A professora Viviane Simioli Medeiros Campos, coordenadora do curso, por seu carinho e compromisso na busca de respostas aos nossos questionamentos.

Aos colegas do Mestrado, com quem convivemos durante o curso e, em particular, aos colegas Clésio Ricardo de Brito e Naciara Pereira Dantas da Fonseca por ter feito parte atuante do grupo de discussões.

Aos familiares e amigos pelo carinho e apoio.

Às colegas de trabalho Débora Suzane de Araújo Faria - pedagoga e Maria José de Oliveira - Professora de Língua Portuguesa do IFRN campus Caicó, por compartilhar saberes e experiências.

Aos alunos do $2^{\circ}$ Ano do curso técnico de nível médio em Eletrotécnica - turma 2M/2011 do IFRN - Campus Caicó, pela colaboração no desenvolvimento das atividades.

\section{Referências}

BARROSO, J. M. (Ed.). Conexões com a Matemática. 1.ed. São Paulo: Moderna, 2010.

BRASIL, Ministério da Educação - Secretaria de Educação Fundamental. Orientações Curriculares para o Ensino Médio - Ciências da Natureza, Matemática e suas Tecnologias. Brasília: MEC/SEF, 2006.

BROUSSEAU, G. Os diferentes papéis do professor. In: PARRA, C; SAIZ, I (Orgs). Didática da Matemática. Porto Alegre: Artmed, 2001.

D'AMBROSIO, U. Informática, Ciências e Matemática, 1999. Disponível em: $<$ http://vello.sites.uol.com.br/tve.htm>. Acesso em: 03 de novembro de 2012.
D'AMBROSIO, U. Sociedade, Cultura, Matemática e seu ensino. Revista da Faculdade de Educação da USP, Educação e Pesquisa. v. 31, no 01, p. 99-120, jan./mar. 2005. Disponível em: $<$ http://redalyc.uaemex.mx/pdf/298/29831108.pdf >. Acesso em: 05 de janeiro de 2013.

MERCADO, L. P. L. (org). Novas tecnologias na educação: reflexões sobre a prática. Maceió: EDUFAL, 2002.

OLIVEIRA, G. P. Transposição Didática: aportes teóricos e novas propostas. In: WITTER, G. P.; FUJIWARA, R. (Org.). Ensino de Ciências e Matemática: análise de problemas. São Paulo: Ateliê Editorial, 2009.

OLIVEIRA, G. P. et al. Estratégias Didáticas em Educação Matemática: as tecnologias de informação e comunicação como mediadoras. Anais do IV Simpósio Internacional de Pesquisa em Educação Matemática - IV Sipem. Brasília: SBEM, 2009.

PCN+ ENSINO MÉDIO. Ciências da Natureza, Matemática e suas Tecnologias. Disponível em: $<$ http://portal.mec.gov.br/seb/arquivos/pdf/Cienc iasNatureza.pdf $>$. Acesso em 07 de outubro de 2012.

SOUZA, J. Novo Olhar - Matemática. 1.ed. São Paulo: FTD, 2010.

VALENTE, J. A. Diferentes usos do computador na educação. 1995. Disponível em: $<$ http://www.mrherondomingues.seed.pr.gov.br/ redeescola/escolas/27/1470/14/arquivos/File/PPP/ Diferentesusosdocomputadoreducacao.PDF $>$. Acesso em: 02 de dezembro de 2012.

VALENTE, J. O Computador na Sociedade do Conhecimento. Campinas, SP: UNICAMP/NIED, 1999.

VÍDEO: TUTORIAL GEOGEBRA - PARTE I. Disponível em: $<$ http://www.youtube.com/watch?v=1v4UXBklw hM>. Acesso em: 15 de setembro de 2012. 